\title{
Three Parts Natural, SeVen Parts Man-MAde: Bayesian ANALysis OF CHINA's GREAT LEAP FoRWARD DEMOGRAPHIC DISASTER
}

\author{
BY
}

\section{DANiEl Houser Barbara SANDS ERTe Xiao*}

\author{
FEBRUARY, 2005
}

\begin{abstract}
$\underline{\text { ABSTRACT }}$
The millions of deaths that occurred during China's great famine of 1959-1961 represent one of the world's greatest civil demographic disasters. Two primary hypotheses have been advanced to explain the famine. One is that China experienced three consecutive years of bad weather while the other is that national policies were wrong in that they reduced and misallocated agricultural production. The relative importance of these two factors to the famine remains controversial among China scholars. This paper uses provincial-level demographic panel data and a Bayesian empirical approach in an effort to distinguish the relative importance of weather and national policy on China's great demographic disaster. Consistent with the qualitative literature in this area, we find that national policy played an overall more important role in the famine than weather. However, we provide new quantitative evidence that weather was also an important factor, particularly in those provinces that experienced excessively wet conditions. (JEL O53, E65)
\end{abstract}

Keywords: China, Famine, Great Leap Forward, Bayesian Analysis, Gibbs Sampling

\footnotetext{
${ }^{*}$ Houser and Xiao: Interdisciplinary Center for Economic Science, Department of Economics, George Mason University, 4400 University Drive, MSN 1B2, Fairfax, VA, 22030; Sands: Department of Economics, University of Arizona, 401 McClelland Hall, Tucson, AZ 85721. Correspondence to: dhouser@gmu.edu, 703.993.4856.
} 


\section{Introduction}

The millions of excess deaths and lost births that occurred during China's great famine of 1959-1961 represent one of the world's greatest civil demographic disasters. Two primary hypotheses have been advanced to explain the famine. One is that China experienced three consecutive years of bad weather while the other is that national policies reduced and misallocated agricultural production (see, e.g., Yao (1999) and Lin (1990) for recent defenses of the respective hypotheses). The relative importance of these two factors to the famine remains widely discussed and, due to an extreme paucity of period data, highly controversial among China scholars. This paper complements existing qualitative literature by using provincial-level demographic panel data, and a Bayesian empirical approach, to provide new evidence on the relative importance of weather and national policy on China’s great famine.

The national policies in place during the famine of 1959-1961 were those of the “Great Leap Forward” (1958-1961) with their goal of achieving dramatic national economic growth. ${ }^{1}$ Policy campaigns advocated such wholesale economic changes as communal organization of rural labor, regional self-sufficiencies, and dual track (smalland large-scale) industrial investment and production. In China's agricultural areas, these policies translated specifically into the formation of rural people's communes, massive earth-working labor organizations, adoption of unorthodox cropping techniques, and accelerated "backyard steel" production campaigns. Altogether, these policies have been criticized for introducing overly aggressive grain procurement policies, ill-advised movements of labor out of agriculture, and poorly structured incentive systems that discouraged agricultural production. Moreover, in the Fall of 1958 Chairman Mao 
suspended the right of peasants to withdraw from their collectives. Lin (1990) argues that this particular national policy, and the incentive effects it generated, accounts for most of the agricultural crisis. The national policy hypothesis is that China was, during the famine period, a very misguided centrally planned economy: China’s government leaders promulgated a series of poorly conceived policies that regional bureaucrats implemented and that caused national famine and, consequently, extraordinary population losses. $^{2}$

The weather hypothesis is that the years 1959-1961 were years of extremely bad weather that led to dramatic crop failures. This hypothesis was put forth very early by Chinese government officials as an explanation for the famine (Communist Party of China (1981)). Since that time, weather has also been suggested by several scholars as an important source of the famine. ${ }^{3}$ In a careful recent study, Yao (1999) concludes that “[weather] should explain a large proportion of the total loss of grain production in [1959-1961]” (p. 1367).

Our aim in this paper is to shed further light on the importance of weather in relation to national policy in the 1959-1961 famine. The approach we take is related to recent work by Lin and Yang (2000) that distinguishes the relative impact of national percapita food availability and urban protection programs on the famine. As in that study, our empirical analysis is based on a panel of mortality rates at the provincial level. The reason is that a province's excess deaths (those above the "normal” level) are known to be closely tied to a province's actual food availability (the amount of their grain output to which they were entitled) during famine periods (see ,e.g., Bongaarts and Cain (1982) and Sen (1981)). While we would prefer to include detailed data on grain production and 
grain movements across regions in our analysis, no such data exist. On the other hand, demographic data for the famine period are well trusted, have been constructed by several different scholars and are relatively clean and complete even at the level of the province.

National policy effects were quite heterogeneous across provinces. Reasons for this include "urban bias" (Lin and Yang, 2000), and the fact that some provinces were extremely radical in their support for central policies while others were more cautious (Teiwes, 1979, 1990). Such differences in local bureaucracies might have resulted in different implementations and consequences of national Leap policies. At the same time, others have suggested that certain policies in place at this time did have broad and fairly homogeneous effects. For example, the peasants' loss of their right to exit cooperatives applied throughout China and affected agricultural productivity in most provinces in a similar way.

This research models a province's mortality rate during the great famine as driven by three factors: (1) central policies common to all provinces; (2) the unique response of a province to that central policy; and (3) a province's weather conditions. Our approach is to specify a model of provincial mortality rates that subsumes these three effects, and then to take this model to annual mortality data that covers the years 1955 to 1965 for 28 of China's 29 major provinces and large cities (we exclude Tibet). We then perform Bayesian inference using Markov Chain - Monte Carlo techniques.

We find that national policy accounted for most of the excess deaths during the famine period, and that there was substantial heterogeneity in its effect among regions. Moreover, our analysis provides new quantitative evidence on weather effects during the Leap period. Some have cast doubt on the importance of drought to the famine, 
particularly because engine-powered irrigation was increasingly common during that period (see, e.g., Lin, 1990, p. 1236). Others, however, have pointed out that many of China's provinces experienced unusually severe typhoons and flooding during the Leap period, and that this led to significant crop failures (see, e.g., Chen, 2000). In fact, the regions we estimate to have been most adversely affected by weather are generally those that experienced unusually wet conditions.

Overall, we find that about $70 \%$ of all excess deaths can be tied to national policy effects. This result reflects a well-known view expressed by Chinese peasants of Hunan during their 1961 conversation with Liu Shaoqi, who was at the time a high leader of the People’s Republic of China. The peasants reported: “The great disaster was three parts natural, and seven parts man-made” (Liu, 1985).

\section{The Model and Inference}

\section{II.A. Motivation}

The primary hypotheses put forth to explain the 1959-1961 famine in China are that it was due to (1) the centralized policies adopted by China's planners; and (2) the way in which the provincial authorities implemented the central policies; and (3) "natural" causes, in particular bad weather. The fact that detailed weather and policy data are unavailable for this period has made it difficult to resolve the relative roles of these effects on the famine. However, since it seems widely accepted that reduced food availability was the source of excess mortality during this period, these same hypotheses are the primary explanations for the famine period's excess deaths. Our goal is to distinguish the three hypotheses through an analysis of provincial level mortality rates. 
To motivate the empirical approach that we adopt in this research, suppose that one had access to an annual scalar index that summarized the influence of national policy on food availability, and therefore mortality rates. In principle, such an index could be constructed by somehow quantifying and aggregating national policy attitudes along dimensions including collectivization, industrial production and urbanization. In the case that such a national policy index existed and was reasonably well accepted it would be straightforward to derive estimates of the national policy effect on mortality rates. For instance, one could use standard regression techniques to obtain estimates of the elasticity of each province's mortality rates with respect to changes in this national policy index. Heterogeneity in these elasticities across provinces would be expected, and one could ask whether their estimated relative values were consistent with prior information about the strength of local governments support for the national initiatives. Since policy and weather are the only two factors believed to have substantially influenced food availability, and therefore mortality, over the famine period, it would seem natural to interpret the amount of demographic variation left unexplained by the national policy effect as due to the weather. Finally, one could assess the validity of these estimates and interpretations by comparing their implications to outside sources of information on national policy and weather effects during the famine period.

Unfortunately, to the best of our knowledge no such national policy index exists. Moreover, any attempt to create one would necessarily be subjective and, consequently, inferences regarding national policy elasticities would likely be highly controversial. On the other hand, since national policies should have a common influence on regions' food availability and therefore mortality rates, we might expect that it is possible to learn about 
national policy effects from common co-movements across regions' demographic time series, even in the event that a policy index cannot be specified a priori.

Procedures to draw inferences about an unobserved index from panel data have been long available (see, e.g., Sargent and Sims (1977), or Stock and Watson (1988, 1991)). This research uses such a method. The main assumptions required to implement our approach are that all of the co-movements between regions' demographic time series are due to the effects of national policies, and that each province's weather effects are uncorrelated with all other provinces' weather effects at all leads and lags. While these assumptions are strong, they have the substantial benefit of allowing us to take a step towards distinguishing quantitatively the relative roles of policy and weather with the available data. Indeed, we provide evidence (see section IV.C.) that our results are broadly consistent with external measures of national policy and weather effects. With respect to the questions that motivate this paper, we are comfortable with the validity of our model and the assumptions that form its foundation.

\section{II.B. The Model}

This research assumes that the crude death rate $d_{i t}$ for each province $i$ and period $t$ depends on national policy and weather provincial level effects according to a simple log additive specification:

$$
\begin{aligned}
& \log d_{i 1}=u_{i}+\gamma_{i} \log (1.0)+e_{i 1} \\
& \log d_{i t}=u_{i}+\gamma_{i} \log c_{t}+e_{i t}, t=2, T .
\end{aligned}
$$

Here, $c_{t}$ is the latent index of the effect of national policies on death rates at year $t$. The coefficient $\gamma_{i}$ is province $i$ 's elasticity of mortality rates with respect to the national 
policy index. For identification purposes, the value of the national policy index in the first year is set to one; the elasticities are measured in relation to this baseline year. The variables $e_{i t}$ measure province specific weather effects on mortality rates. Finally, $u_{i}$ is province $i$ 's log death rate in the absence of unusual national policy or weather effects.

\section{II.C. Distributional Assumptions}

Let $y_{i t}$ denote the log crude death rates, and let $z_{t}$ denote the log of the latent index. We implement our model under the following assumptions.

$$
\begin{aligned}
y_{i t} & =u_{i}+\gamma_{i} z_{t}+e_{i t}, i=1, \ldots, N ; t=1, \ldots, T . \\
e_{i t} & =\rho_{i} e_{i, t-1}+v_{i t}, i=1, \ldots, N ; t=2, \ldots, T . \\
v_{i t} & \sim N\left(0, \sigma_{i v}^{2}\right) . \\
e_{1} & \sim N\left(0,0.25^{2}\right) . \\
z_{t} & \sim N(0,1), \text { independently for } t=2, \ldots, T . \\
z_{1} & =0 .
\end{aligned}
$$

The parameter $\rho_{i}$ captures temporal correlation in weather effects within a province. We assume that $z_{t}$ is independent over time because the famine period includes policy changes that likely affected its process in ways that are difficult to specify a priori. The distribution of $e_{1}$ is fixed because its variance is only weakly identified. We chose a standard deviation for this distribution that seemed reasonable given that the dependent variable is log of deaths per 1000 in the population.

The initial value of each national effect index is pegged at unity, which implies that $z_{t}$ is pegged at zero, and this is an identifying restriction. Another identifying restriction is that the latent index is uncorrelated with the province specific effects at all 
leads and lags. Under these conditions the model is identified (see, e.g., Stock and Watson (1991) for elaboration of identifying conditions in single index models).

\section{II.D. Bayesian Inference}

In this research we adopt a Bayesian approach to inference. One reason is that we have a large number of provinces (28) and province specific parameters but we use a relatively small amount of data for each province (11 years). Bayesian inference is exact in small samples.

Bayesian inference stems from the joint posterior distribution of the parameters, latent variables and unobserved variables conditional on the observed data. Let $Y$ denote the set of logs of observed data for all provinces and let $Y^{*}$ denote the set of logs of missing data. Note that $Y^{*} \cup Y=\left\{y_{i t}\right\}_{i=1, N}$. With this notation the joint posterior distribution of interest can be expressed as follows.

$$
\begin{aligned}
& p\left(\left(u_{i}, \gamma_{i}, \rho_{i}, \sigma_{i v}^{2}\right)_{i=1, N},\left(z_{t}\right)_{t=1, T}, Y^{*} \mid Y\right) \\
& \propto p\left(\left(y_{i t}\right)_{i=1, N} \mid\left(u_{i}, \gamma_{i}, \rho_{i}, \sigma_{i v}^{2}\right)_{i=1, N},\left(z_{t}\right)_{t=1, T}\right) \\
& \quad \cdot p\left(\left(z_{t}\right)_{t=1, T} \mid\left(u_{i}, \gamma_{i}, \rho_{i}, \sigma_{i v}^{2}\right)_{i=1, N}\right) p\left(\left(u_{i}, \gamma_{i}, \rho_{i}, \sigma_{i v}^{2}\right)_{i=1, N}\right) .
\end{aligned}
$$

The first two terms after the proportionality sign comprise the so-called "complete-data" likelihood function. This is the likelihood function that we would write down if all of the $c_{t}$ and unobserved variables were observed. The final term in the product after the proportionality sign is the prior distribution for the models' parameters. Next we develop the expression for the complete data likelihood function and specify our priors.

The complete data likelihood function derives directly from the distributional assumptions made in (3). It is: 


$$
\begin{aligned}
& p\left(\left(y_{i t}\right)_{i=1, N} \mid\left(u_{i}, \gamma_{i}, \rho_{i}, \sigma_{i v}^{2}\right)_{i=1, N},\left(z_{t}\right)_{t=1, T}\right) p\left(\left(z_{t}\right)_{t=1, T} \mid\left(u_{i}, \gamma_{i}, \rho_{i}, \sigma_{i v}^{2}\right)_{i=1, N}\right)= \\
& \left(\prod_{i=1, N} \frac{1}{\left(2 \pi \sigma_{i v}^{2}\right)^{(T-1) / 2}}\right) \exp \left\{-\left(\sum_{i=1}^{N} \frac{1}{2 \sigma_{i v}^{2}} \sum_{t=2}^{T}\left(y_{i t}-u_{i}-\gamma_{i} z_{t}-\rho_{i}\left(y_{i, t-1}-u_{i}-\gamma_{i} z_{t-1}\right)\right)^{2}\right)\right\} \\
& \cdot \frac{1}{\left(2 \pi(0.25)^{2}\right)^{N / 2}} \exp \left\{\sum_{i=1, N} \frac{-1}{2(0.25)^{2}}\left(y_{i, 1}-u_{i}\right)^{2}\right\} \frac{1}{(2 \pi)^{(T-1) / 2}} \exp \left\{-\frac{1}{2} \sum_{t=2}^{T} z_{t}^{2}\right\}
\end{aligned}
$$

In this research we employ the following convenient conjugate and proper priors.

$$
\begin{aligned}
u_{i} & \sim N(1,4), i=1, \ldots, N ; \\
\gamma_{i} & \sim N(1,4), i=1, \ldots, N ; \\
\rho_{i} & \sim U[-0.99,0.99] ; \\
\sigma_{i v}^{2} & \sim 0.25 / \chi^{2}(1) .
\end{aligned}
$$

These priors are proper but in fact quite diffuse with respect to our questions. The reason is that the mortality data that we use is in deaths per 1000 in the population. Hence, recalling also that the model is specified in terms of log death rates, the prior on $u_{i}$ says that we believe the "typical" rate of deaths is likely between zero and 150 per thousand people in each population. Our prior on the elasticity states that we do not expect elasticities in excess of 5 or less than -4 , and that we expect elasticities to be around unity. The prior on $\rho_{i}$ reflects our assumption that the mortality process is stationary over our sample period. The prior on $\sigma_{i v}^{2}$ is that its value is around 0.25 . It is clear from the characteristics of the posterior distributions reported below that, with the possible exception of some $\rho_{i}$, all of the priors are overwhelmed by the information contained in the data. ${ }^{4}$ 


\section{II.E. The Gibbs Sampler}

The joint posterior density of interest is formed by taking the product of (5) and the appropriate prior distributions implied by (6). The goal is to derive from this joint posterior the marginal posterior distribution of the latent index and each parameter. Although this is difficult to do analytically, Gibbs sampling is one of several Markov Chain - Monte Carlo (MCMC) procedures that can be used to find arbitrarily good numerical approximations to marginal posterior distributions (for reviews see Geweke and Keane (1999) or Chib and Greenberg (1996); for applications to econometric models see e.g., Houser (2003), Houser, Keane and McCabe (2004) and Houser et. al. (2005)).

The Gibbs sampler, in our case with data augmentation (see, e.g., Tanner and Wong (1987)), is implemented by repeatedly sampling from the complete conditional posterior density of each parameter as well as the conditional posterior density of the unobserved data. Under weak regularity conditions that our model satisfies such sampling will generate a Markov Chain that converges to the joint posterior distribution and from which one can extract the desired marginal posterior distributions. Below we provide the set of conditional posteriors needed to implement the algorithm. Regularity conditions and results regarding convergence of the Gibbs sampler are available in Tierney (1994). Readers uninterested in technical details regarding implementation of the Gibbs sampler may skip the remainder of this section.

\section{II.F. Implementing the Gibbs sampler}

Complete conditional posterior of $\left\{u_{i}, \gamma_{i}\right\}, i \in\{1, \ldots, N\}$. 
To form this complete conditional posterior one assumes that everything that enters the likelihood is known except the value of $\left\{u_{i}, \gamma_{i}\right\}$ for some $i \in\{1, \ldots, N\}$. Under this condition, the kernel of the distribution of this pair of random variables is, from the complete data likelihood and prior, given by:

$$
\begin{aligned}
& \exp \left\{-\frac{1}{2 \sigma_{i v}^{2}} \sum_{t=2}^{T}\left(y_{i t}-u_{i}-\gamma_{i} z_{t}-\rho_{i}\left(y_{i, t-1}-u_{i}-\gamma_{i} z_{t-1}\right)\right)^{2}\right\} \\
& \cdot \exp \left\{\frac{-1}{2(0.25)^{2}}\left(y_{i, 1}-u_{i}\right)^{2}\right\} \exp \left\{-\frac{1}{8}\left(u_{i}^{2}+\gamma_{i}^{2}\right)\right\} .
\end{aligned}
$$

It is easy to sample from this density using rejection methods. In particular, draws from (7) can be generated by sampling from the source density implied by the first exponential kernel, and then accepting each such draw with the probability implied by the product of the second two kernels when evaluated at the drawn values.

Sampling from the distribution implied by the first exponential kernel is easy. The kernel implies that $\left\{u_{i}, \gamma_{i}\right\}$ is a normally distributed random vector with mean

$$
\left(u_{i}, \gamma_{i}\right) \sim N\left(\left(X_{i}^{\prime} X_{i}\right)^{-1} X_{i}^{\prime} W_{i}, \sigma_{i v}^{2}\left(X_{i}^{\prime} X_{i}\right)^{-1}\right)
$$

where $W_{i}$ is a vector with T-1 rows, $W_{i}(t)=y_{i t}-\rho_{i} y_{i, t-1},(t=2, T)$, and $X_{i}$ is a T-1 X 2 matrix, $X_{i}(t)=\left[1-\rho_{i}, z_{t}-\rho_{i} z_{t-1}\right],(t=2, T)$. It is easy to draw from this bivariate normal distribution using standard techniques.

Complete conditional posterior for $\rho_{i}$. 
Conditional on all other quantities being known, it is clear from (5) and (6) that the density of each $\rho_{i}$ is truncated normal with bounds $\{-0.99,0.99\}$. The mean of the (untruncated) normal distribution is

$$
\sum_{t=2, T}\left(y_{i, t}-u_{i}-\gamma_{i} z_{t}\right)\left(y_{i, t-1}-u_{i}-\gamma_{i} z_{t-1}\right) / \sum_{t=2, T}\left(y_{i, t-1}-u_{i}-\gamma_{i} z_{t-1}\right)^{2}
$$

and the variance is

$$
\sigma_{i v}^{2} / \sum_{t=2, T}\left(y_{i, t-1}-u_{i}-\gamma_{i} z_{t-1}\right)^{2}
$$

Samples from the truncated distribution are generated by drawing from the untruncated density and then rejecting any draw that exceeds 0.99 in absolute value.

Complete conditional posterior for $\sigma_{i}^{2}$.

It is easy to show that (5) and (6) together imply

$$
\frac{0.25+\sum_{t=2}^{T}\left(y_{i t}-u_{i}-\gamma_{i} z_{t}-\rho_{i}\left(y_{i, t-1}-u_{i}-\gamma_{i} z_{t-1}\right)\right)^{2}}{\sigma_{i v}^{2}} \sim \chi^{2}(T) .
$$

It is easy to draw from this distribution using standard software.

Complete conditional posterior for $z_{t}, 1<t \leq T$.

We choose to draw the $z_{t}$ one-by-one, taking all other $z_{j}, j \neq t$, given during the draw. Under this condition it can be seen from (5) and (6) that if $1<t<T$ then $z_{t}$ enters the posterior distribution in the product of $2 N+1$ Gaussian kernels, and $z_{T}$ enters in the product of $N+1$ Gaussian kernels. Hence, each $z_{t}$ has a complete conditional normal 
density, with mean and variance given by repeatedly applying the standard formula for the product of two such Gaussian kernels (see, e.g., Box and Tiao (1992), p. 74-75). It is easy to compute each $z_{t}$ 's mean and variance and then to draw from the appropriate normal distribution.

Complete conditional posterior for the unobserved data.

There is one observation missing in our data set: the death rate in Hubei province in 1955. From (5), the density from which this initial observation is drawn is the product of two Gaussian kernels:

$$
\exp \left\{-\frac{\rho_{i}^{2}}{2 \sigma_{i v}^{2}}\left(y_{i 1}-u_{i}-\left(y_{i 2}-u_{i}-\gamma_{i} c_{2}\right) / \rho_{i}\right)^{2}\right\} \exp \left\{\frac{-1}{2\left(0.25^{2}\right)}\left(y_{i 1}-u_{i}\right)^{2}\right\} .
$$

Thus, the missing data has a normal distribution with a readily computed mean and variance.

Inference about marginal posterior distributions.

Let $\theta$ represent an arbitrary parameter included in our model, and let $\theta^{(j)}$ denote the draw of this parameter on the $j$ th cycle of the Gibbs sampler. Suppose the Gibbs sampler is run for $\mathrm{J}$ cycles in total, and that the sampler is known to have converged after the first $k$ cycles. Then it turns out that reasonable estimates of the mean and standard deviation of the marginal posterior distribution of any function $g(\theta)$ of this parameter are $\bar{g}(\theta)=\frac{1}{J-k} \sum_{j=k+1}^{J} g\left(\theta^{(j)}\right) \quad$ and $\quad \hat{\sigma}_{g(\theta)}=\sqrt{\frac{1}{J-k-1} \sum_{j=k+1}^{J}\left(g\left(\theta^{(j)}\right)-\bar{g}(\theta)\right)^{2}}, \quad$ respectively.

These are the formulas we use to derive the means and standard deviations of the 
marginal posterior distributions reported below. For example, inferences about the latent state $c_{t}$ are formed by using $g\left(z_{t}\right)=\exp \left(z_{t}\right)$. For further discussion of the calculation of posterior moments from Gibbs sampling output see Geweke (1992).

\section{The Data}

The data used in our analysis are drawn from a set constructed from Chinese sources by the second author and described in detail in Sands and Buelow (1997). These same data were used by Peng (1987) and Lin and Yang (2000) in their Leap investigations. The data set includes annual crude birth rates, crude death rates, and net migration rates for 28 of China's 29 provinces and major cities (Tibet is excluded for lack of data) and covers the years beginning in 1955 and ending in 1982. Our research focuses on the years beginning in 1955 and ending in 1965. These years cover the period leading up to, including the Leap, and shortly thereafter. We do not use data beyond 1965 because of the significant policy changes that then occurred.

Table 1 provides mortality rates by province for the years 1955 to 1965 . There are 11 annual observations for death rates for each province except Hubei, where we are missing data on the death rate in 1955. Casual observation makes clear that there was substantial heterogeneity between provinces and large cities in their mortality rates over our sample period. The average number of deaths per 1000 people in the population ranged from a low of 6.8 in Shanghai to a high of 21.8 in Sichuan. These regions are notable in that Shanghai is an important urban area while Sichuan was China's most highly populated province where about half of the famine's deaths are believed to have occurred. Shanghai experienced the lowest standard deviation in death rates over our 
sample period, 0.8, while Sichuan's was 15.6 and second only to Anhui's 17.8. Not only were Shanghai's mortality rates almost constant over the Leap period but they were also lower in 1960 than in 1955. Sichuan experienced its greatest death rates in 1960 and lowest in 1955 . The years 1959 and 1960 are often taken to be those where the greatest deaths occurred due to national policy mistakes, yet seven of the 28 provinces and large cities in our sample experienced their greatest mortality rates outside of those years. Still, 17 regions reported highest mortality rates during 1960.

\section{Results}

We coded our Gibbs sampler in FORTRAN 90 and made extensive use of IMSL subroutines. We implemented the algorithm on a Pentium II 300MHz workstation. We ran the Gibbs sampler for 40,000 cycles. A complete 40,000 cycle run took about five minutes of processor time. Inspection of the draw sequences satisfied us that the sampler had converged by cycle 20,000. Our findings are based on the sampler's last 20,000 cycles. The FORTRAN software that we used and the complete draw sequences are available from the authors on request.

\section{IVA. Inferences about Indices and Elasticities}

Figure 1 plots in solid lines the means of the marginal posterior distributions of the national policy mortality index. The dashed lines are located two posterior standard deviations above and below the posterior mean. The values of the mortality index are, relative to their posterior standard deviations, near unity in all years except 1959 and 1960, when they are larger, and 1962 when the value is smaller. The posterior mean of 
the mortality index takes its greatest value in 1960 at 1.34 . This implies that a province with unit national policy elasticity would have experienced, ceteris paribus, about a 34\% greater death rate in 1960 than they did in 1955 due to effects of China's central policies.

Broadly, our evidence is that the national policy effect on deaths was no different during the years from 1956 to 1958 than it was in 1955 . Also, from 1962 on it seems that national policy was not worse for mortality rates than it was in 1955 . However, our findings suggest that national policy did have deleterious effects during the three years beginning in 1959 and ending in 1961. Evidence as to which regions seem to have been adversely affected by national policy is drawn from our inference with respect to national policy elasticities.

Table 2 provides the posterior means and standard deviations for the national policy elasticities and other parameters of each province's mortality rate models. The elasticities' posterior means range from 4.2 in Anhui to 0.1 in Shanghai. These elasticities (in combination with national policy effect estimates) suggest that, ceteris paribus, in 1960 national policies acted to increase the death rate in Anhui over its 1955 level by about 140\%, while the same year in Shanghai death rates increased by only around 3\% due to national policies.

Table 2 also indicates whether each marginal posterior elasticity density has more than $95 \%$ of its mass to the right of zero, and whether over $95 \%$ of its mass lies to the right of one. It turns out that 17 elasticity distributions are in the former group and, of those, seven are in the latter. The high elasticity provinces are Gansu, Qinghai, Henan, Hunan, Guizhou, Guangxi and Anhui. The three urban centers in our sample, Beijing, Shanghai and Xinjiang, are all estimated to have very low elasticities. 


\section{IV.B. National Policy Effects on Mortality}

Our analysis enables us to draw inferences about the number of deaths that can be attributed to national policies both within each of our 28 regions and, consequently, in aggregate. Recalling equation (2), we have that deaths in region $i$ evolve according to

$$
\log d_{i t}=u_{i}+\gamma_{i} \log c_{t}+e_{i t}
$$

where $d_{i t}$ is number of deaths per 1000 in the population and with $c_{1}=1$. Hence, if $\hat{\gamma}_{i}$ and $\hat{c}_{t}$ represent point estimates of the elasticity and national policy index, respectively, then an estimate of the impact of national policy on the number of deaths in year $t$ is given by

$$
\frac{p o p_{i t}}{1000}\left\{d_{i t}-\exp \left(\log d_{i t}-\hat{\gamma}_{i} \log \hat{c}_{t}\right)\right\}
$$

where pop $_{i t}$ is the population of region $i$ in year $t$.

Our interest is in comparing the mortality impact implied by (9) to the total number of excess deaths that occurred over the Leap period. To do this some degree of arbitrariness is unavoidable. In particular, we must determine (a) point estimates for the elasticities and indices involved in (9); and (b) a measure of excess deaths. We choose to use the posterior means for the $\gamma_{i}$, as reported in Table 2, as our elasticity point estimates, and similarly the posterior means as depicted in Figure 2 are the states' point estimates. Then, since $u_{i}$ represents the log death rate absent unusual national policy or weather effects, we define the number of excess deaths in province $i$ as the difference between the actual number of deaths in that province and the number implied by (the appropriate transformation of) the posterior mean of $u_{i}$. The numbers of excess deaths 
that arise from this definition are very close to the numbers that others have reported using alternative procedures (see, e.g., Yao (1999) or Lin and Yang (2000)).

Table 3 lists China's 28 provinces, their actual and estimated expected numbers of deaths from 1959-1961, the estimated number of excess deaths over this same period, and the estimated number of those excess deaths due to national policy and weather. Based on our definitions and population estimates we find that, in aggregate, from 1959 to 1961 China suffered about 14.8 million excess deaths. Of those, about $71 \%$ seem attributable to effects stemming from national policies. We find that only one region, Shaanxi, did not experience excess deaths during the period 1959-1961. Within the remaining regions, national policy often predicts all of their excess deaths over the famine period. In seven provinces the number of excess deaths predicted by the model's national policy effect is greater than the number that actually occurred. We interpret this as suggesting that the weather in those provinces was able to offset the national policy effect. Our results indicate that Shanghai is least affected by national policy in percentage terms, with only $11 \%$ of her excess deaths tied to this effect. Nearly all of Anhui's deaths seem attributable to national policy, while Sichuan's excess deaths seem attributable to weather and national policy in roughly equal proportions.

\section{IV.C. Validity}

The purpose of this section is to use external measures of national policy effects and weather during the famine period in order to argue that our model and results are reasonable. 


\section{IV.C.1. Central Policy}

Several studies in the qualitative literature have argued that the famine-inducing policies pursued during the Great Leap Forward were not applied in the same way in every region. For example, regions with large urban populations, particularly Beijing, Tianjin, and Shanghai, were especially protected from food shortages (see, e.g., Lin and Yang (2000)). Also, leaders of at least four regions are generally agreed to have advocated "radical” forms of Leap policies. These regions are Sichuan province, Anhui province, Shanghai and Henan province (see, e.g., Domenach (1995) and Teiwes (1979 and 1993)).

On the basis of this qualitative literature we would expect to find relatively low national policy elasticities for the three major municipalities and relatively high elasticities for the four "radical" regions. Note that Shanghai municipality is included in both groups, as it is generally considered a protected municipality with a radical leader in the qualitative literature. From Table 2, Beijing, Shanghai and Tianjin are all estimated to have particularly small mortality elasticities. Hence, our estimates suggest that the protection Shanghai received was more important to its mortality rates than any radical tendencies of its leader. With respect to the three known radical provinces, we find that Anhui has the largest elasticity among the regions in our sample. Henan and Sichuan are estimated to have the fifth and sixth highest elasticities, respectively.

\section{IV.C.2. Weather}

We interpret the residuals in equations (1) and (2) as capturing the effect of weather on famine-based mortality. A natural way to assess the validity of this interpretation is to compare the behavior of the estimated residuals (weather effects) to external information 
on weather conditions during the famine period. Previous studies on the effects of weather during China's famine have used indirect measures such as the number of sown acres affected by natural disaster (see, e.g., Lin (1990) and Yao (1999)). In our study we use a more direct measure, namely, precipitation indices collected from a remarkable volume reporting drought and flood incidences in China from 1470 to 1977 (Central Meteorological Institute (1981)).

This volume reports annual weather indices classified into 5 grades for 120 regions of China for 500 years. The five grades are: grade 1 -- very wet, grade 2 -- wet, grade 3 -- normal, grade 4 --dry, and grade 5 -- very dry. The 120 regions are located in China's 30 provinces (including Taiwan and Tibet), and thus province-level measures are achieved by averaging sub-province measures. While the indices for the 500 years were constructed using documentary historical data from yearbooks, diaries, and gazettes, when they were compared with data obtained from an analysis of instrumental records for the period 1951-1974, they were found to be similar and thus credible (Wang and Zhao (1981)). Most important for us, those latter instrument-measured years cover those of the Great Leap Forward.

The estimated weather effects are the values of the residuals implied by equation (8) when the parameters of that equation are set equal to their posterior means. We compare the behavior of these residuals to the weather data. Our approach to this comparison is to average each province's residuals and precipitation index across the years 1959-1961. This procedure is appropriate because the residuals generally demonstrate positive serial correlation (see Table 2) and it turns out that the weather data are also generally positively serially correlated. ${ }^{5} \quad$ Hence, averaging across years should 
improve the estimate of each province's weather condition and should also provide a reasonable reflection of each province's actual weather over the three famine years.

We compared the average estimated residual series to a series that indicated whether each province was unusually wet and a series that indicated whether a province was unusually dry, on average, over the famine years. To construct these variables we first used the natural aphine transformation to map the raw average weather for each province over the famine years to the interval $[-1,1]$. A province was wetter than normal, on average over the famine years, if its average was less than zero, and dryer than average if its average was greater than zero. Hence, if $\mathrm{W}$ represents a province's average, the wetness variable was set to $-\min (\mathrm{W}, 0)$, and the dryness variable to $\max (\mathrm{W}, 0)$. A value of one, say, for the wetness variable would indicate that the province was extremely wet over the famine years, while a value of zero would indicate that it was not wet, and might have been dry.

The dryness series is not statistically significantly correlated with our estimated weather effects. This is consistent with the observation made by Lin (1990) that enginepowered irrigation was increasingly common over the famine period. However, excluding Sichuan province, an outlier discussed below, it turns out that the wetness series is a statistically significant predictor of our estimated weather effects. Figure 2 plots the residual and wetness series, and provides evidence that the two series are connected. More formally, a simple ordinary least squares regression of the average residual against a constant and the wetness series generates a wetness coefficient of 0.25 $(p<0.05)^{6}$, and the simple correlation between the two series is 0.39 . 
With respect to Sichuan, the qualitative literature acknowledges it as a major population loss area during the Leap, and we also estimate that it contributed over five million excess deaths during famine years, around 36\% of the nation's total (see Table 3). Although Sichuan has a relatively high national policy elasticity, it nevertheless turns out that only about half of these deaths seem attributable to national policy effects. Moreover, our weather data indicate that Sichuan experienced normal conditions during the famine years. So what happened in Sichuan?

One possible explanation is tied to Sichuan's large quantity of grain exports. The data on Leap regional grain movements have been troublesome because many of the numbers from the period are either exaggerated or unavailable. However, recent research based on newly recovered estimates suggests that perhaps the province's population was indeed "sold down the river" by its grain exports.

Another possibility is that Sichuan experienced a devastating disease outbreak. Such a disease could have impeded a current year's harvest and made it difficult to plant crops the subsequent year. Hence, even a relatively short lived but severe disease can generate two years of reduced agricultural output and substantially increased death rates. In fact, 1957 and 1958 saw a worldwide influenza pandemic that had its first documented incidence in Guizhou province (next to Sichuan) ${ }^{8}$. Note though that China was not a member of the World Health Organization in the 1950s or 1960s, so that detailed reports regarding her population's experience with the flu have been difficult to obtain. 


\section{Conclusion}

This paper presented a first attempt to quantify the relative influences of national policy and weather on the deadly famine that occurred in China during the Great Leap Forward period. Our study was based on annual crude death rate data from 28 Chinese provinces over the years from 1955 to 1965 . We adopted a parametric statistical approach and used Bayesian techniques to draw inferences about our models’ parameters. Although our analysis required several strong assumptions, we provided evidence that argued our results are valid.

Our quantitative results refine current understanding of the Leap period, yet are broadly consistent with the views expressed in the Great Leap Forward qualitative literature. We find that, in aggregate, about two-thirds of excess deaths that occurred over the Leap period seem to be attributable to national policies. We also find substantial province-level heterogeneity in the national policy effect. The regions that we identified as essentially unresponsive to changes in national policy, particularly the large cities, have been identified by others in qualitative research as "protected." Similarly, those regions that seemed most sensitive to national policy effects, particularly Anhui, had been identified by previous research as "radical” provinces whose leaders enacted national policies aggressively. ${ }^{9}$

Our results regarding weather effects are novel. To our knowledge we are the first to provide quantitative evidence that, on average, the areas most adversely affected by weather tended to be those that reported unusually wet conditions during the famine years. Sichuan is an outlier whose excess deaths are not easily explained in this way. The 
source of Sichuan province's disaster presents an interesting open puzzle that future qualitative and quantitative research should address.

Our quantitative findings generally suggest more about China's regional and national political machinations than can be matched in the qualitative literature, and this might also provide fertile ground for future investigations. For example, Gansu, Qinghai, Guangxi, and Guizhou provinces all show relatively high policy elasticities. On the other hand, Shanxi, Shaanxi, Heilongjiang, and Jilin provinces show relatively low policy elasticities. It would be very interesting to conduct a comparative analysis of the local policies adopted in high and low elasticity regions during the Leap period. 


\section{References}

Ashton, Basil, Kenneth Hill, Alan Piazza, and Robin Zeitz. (1984) 'Famine in China, 1958-61'. Population and Development Review 10(4), 613-645

Becker, Jasper. (1996) Hungry Ghosts. Praeger Press, New York

Bernstein, Thomas B. (1984) 'Stalinism, Famine, and Chinese peasants, Grain

procurement during the Great Leap Forward.' Theory and Society 3, 339-77

Bongaarts, John and Mead Cain. (1982) 'Demographic Responses to Famine,' in Kevin M. Cahill, M.D. (ed.), Famine, Orbis Books, Maryknoll, pp. 44-59

Box, G. and G. Tiao. (1992) Bayesian Inference in Statistical Analysis. John Wiley and Sons, Inc. New York.

Carlson, Dennis G. (1982) 'Famine in History: With a Comparison of Two Modern

Ethiopian Disasters', in Cahill, Kevin M. (ed.) Famine, Orbis Books, Maryknoll, pp. 1-12

Central Meteorological Institute, Beijing University, Nanjing University, etc. (1981) Zhongguo Jinwubainian Hanlao Fenbu Quanji (Yearly Charts of Dryness/Wetness in China for the last 500-Year Period). Atlas Press, Beijing

Chan, Alfred. (1992) 'The campaign for agricultural development in the Great Leap Forward, a study of policy-making and implementation in Liaoning.' China Quarterly 129, pp. 52-72

Chen, Donglin. (2000) “ "Three years natural disaster" and "Great Leap Forward" ” Chinese Communist Party History Material 4, (in Chinese)

Chib, S. and E. Greenberg. (1996). Markov Chain Monte Carlo Simulation Methods in Econometrics. Econometric Theory; v12 n3 August 1996, pp. 409-31.

Chow, Gregory C. and Yum K. Kwan. (1996) "Economic Effects of Political Movements in China: Lower Bound Estimates". Pacific Economic Review 1:1, pp. 3-11.

Communist Party of China. Central Committee. (1981) Decisions on Several Historical Issues of the Communist Party of China since the Founding of the Republic. People's

Press, Beijing.

Domenach, Jean-Luc. (1995) The Origins of the Great Leap Forward, The Case of One

Province. Westview Press, Boulder 
Geweke, J. (1992). Evaluating the Accuracy of Sampling-Based Approaches to the Calculation of Posterior Moments. In J.M. Bernardo, J.O. Berger, A.P. Dawid and A.F.M. Smith (eds.), Bayesian Statistics 4. Oxford: Oxford University Press.

Geweke, J. and M. Keane. (1999). Computationally intensive methods for integration in econometrics. In J. Heckman and E. Leamer (eds), Handbook of Econometrics, Vol. 5. North Holland.

Houser, Daniel. (2003). Bayesian analysis of a dynamic stochastic model of labor supply and saving. Journal of Econometrics. April, 113:2. 289-335.

Houser, D., A. Bechara, M. Keane, K. McCabe and V. Smith. (2005). Identification of individual differences: An algorithm with application to Phineas Gage. Games and Economic Behavior. Forthcoming.

Houser, D., M. Keane and K. McCabe. (2004). Behavior in a dynamic decision problem: An analysis of experimental evidence using a Bayesian type-classification algorithm. Econometrica. 72:3, 781-822.

Krusell, P. and Jose-Victor Rios-Rull. (1999). On the Size of U.S. Government: Political Economy in the Neoclassical Growth Model. The American Economic Review, December, 1156-1181.

Lardy, Nicholas R. (1987) 'The Chinese Economy Under Stress, 1958-1965,' in Roderick MacFarquhar and John K. Fairbank (eds.), The Cambridge History of China, Volume 14, Cambridge University Press, Cambridge, pp. 144-184

Li, Choh-ming. (1962) The State Statistical System of Communist China. University of California Press, Berkeley

Lin, Justin Yifu and Dennis Tao Yang. (2000) 'Food Availability, Entitlements and the Chinese Famine of 1959-1961'. The Economic Journal 110 (January), pp. 136-158

Liu, Shaoqi. (1985) 'Extended Central Working Conference Speech.” In, Liu Shaoqi Anthology. Vol II., Renming Chubanshe, pp. 337 (in Chinese)

MacFarquhar, Roderick. (1983) The Origins of the Cultural Revolution II, The Great Leap Forward 1958-1960. Oxford University Press, London

Oksenberg, Michel. (1969) 'Local Leaders in Rural China, 1962-1965: Individual Attributes, Bureaucratic Positions, and Political Recruitment' in A. Doak Barnett, editor, Chinese Communist Politics in Action, pp. 155-215

Oksenberg, Michel. (1974) 'Methods of Communication Within the Chinese Bureaucracy', China Quarterly 57, pp. 1-39 
Peng, Xizhe. (1987) 'Demographic Consequences of the Great Leap Forward in China's Provinces'. Population and Development Review 13(4), pp. 639-670

Sands, Barbara and Sven Buelow. (1997) 'Recounting China’s Great Leap Forward Casualties', University of Arizona working paper

Sargent, T.J. and C. A. Sims (1977), "Business Cycle Modeling without Pretending to Have Too Much a-priori Economic Theory.” In C. Sims et. al., New Methods in Business Cycle Research. Minneapolis: Federal Reserve Bank of Minneapolis.

Sen, Amartya. (1981) Poverty and Famines: An Essay on Entitlement and Deprivation. Oxford: Clarendon Press.

Stock, J. H. and M. W. Watson (1988). “Testing for Common Trends.” Journal of the American Statistical Association, 84 (404), 1097-1107.

Stock, J. H. and M. W. Watson (1991). "A Probability Model of the Coincident Economic Indicators.” In Kajal Lahiri and Geoffrey H. Moore, eds., Leading Economic Indicators: New Approaches and Forecasting Records. Cambridge, England: Cambridge University Press.

Tanner, M.A. and W.H. Wong (1987). “The Calculation of Posterior Distributions by Data Augmentation.” Journal of the American Statistical Association. 82: 528-550.

Tierney, L. (1994). Markov Chains for Exploring Posterior Distributions. The Annals of Statistics, 22, 1701-32.

Teiwes, Frederick C. (1979) Politics and Purges in China. Rectification and the Decline of Party Norms 1950-1965. M.E. Sharpe, Inc., White Plains

Teiwes, Frederick C. (1993) 'Leaders, Institutions, and the Origins of the Great Leap Forward'. Pacific Affairs 66(2), pp. 244-254

Walker, Kenneth R. (1984) Food Grain Procurement and Consumption in China. Cambridge University Press, Cambridge

Wheatcroft, S.G. (1999) 'The Soviet Famines of 1931-3 and the Chinese Famines of 1959-1961 in comparative historical and regional perspectives'. Paper presented to the AASCPCS/ANZSA 1998 International Conference on Communist and Post-Communist Societies, Melbourne, July 7-10, 1998

Yao, Shujie. (1999) 'A Note on the Causal Factors of China's Famine in 1959-1961'. Journal of Political Economy, vol. 107, no. 6, pt. 1

Zhongguo Renkou (China Population Volumes, 32 volumes). (1987-1991) Zhongguo Caizheng Jingji Chubanshe, Beijing 
Table 1. Crude Mortality Rates by Province (1955-1965)

\begin{tabular}{|c|c|c|c|c|c|c|c|c|}
\hline & \multirow[b]{2}{*}{ Province } & \multirow[b]{2}{*}{ Num of Obs. } & \multicolumn{6}{|c|}{ Number of Deaths per 1000} \\
\hline & & & Mean & Std. Dev. & Min & Year & Max & Year \\
\hline 1 & Heilongjiang & 11 & 10.2 & 1.5 & 8.0 & 65 & 12.8 & 59 \\
\hline 2 & Jilin & 11 & 10.3 & 1.7 & 7.5 & 56 & 13.4 & 59 \\
\hline 3 & Liaoning & 11 & 9.8 & 3.0 & 6.6 & 56 & 17.5 & 61 \\
\hline 4 & Neimenggu & 11 & 9.7 & 1.3 & 7.9 & 56 & 11.8 & 64 \\
\hline 5 & Gansu & 11 & 15.9 & 9.6 & 8.2 & 62 & 42.5 & 60 \\
\hline 6 & Shaanxi & 11 & 11.3 & 2.1 & 8.7 & 61 & 16.0 & 64 \\
\hline 7 & Qinghai & 11 & 14.0 & 9.5 & 5.3 & 62 & 40.7 & 60 \\
\hline 8 & Ningxia & 11 & 11.7 & 2.4 & 8.5 & 62 & 15.8 & 59 \\
\hline 9 & Henan & 11 & 13.7 & 8.6 & 8.1 & 62 & 39.0 & 60 \\
\hline 10 & Shandong & 11 & 14.3 & 4.1 & 10.2 & 65 & 23.6 & 60 \\
\hline 11 & Hunan & 11 & 14.0 & 5.6 & 10.2 & 62 & 29.4 & 60 \\
\hline 12 & Hubei & 10 & 11.5 & 3.8 & 8.8 & 62 & 21.2 & 60 \\
\hline 13 & Jiangxi & 11 & 12.1 & 2.2 & 9.4 & 65 & 16.2 & 55 \\
\hline 14 & Zhejiang & 11 & 9.7 & 1.5 & 7.9 & 63 & 12.6 & 55 \\
\hline 15 & Jiangsu & 11 & 11.8 & 2.8 & 9.0 & 63 & 18.4 & 60 \\
\hline 16 & Guizhou & 11 & 19.8 & 11.4 & 11.6 & 62 & 52.3 & 60 \\
\hline 17 & Sichuan & 11 & 21.8 & 15.6 & 9.2 & 55 & 54.0 & 60 \\
\hline 18 & Guangxi & 11 & 14.3 & 6.0 & 9.0 & 65 & 29.5 & 60 \\
\hline 19 & Guangdong & 11 & 10.0 & 2.5 & 6.8 & 65 & 15.8 & 60 \\
\hline 20 & Beijing & 11 & 8.6 & 1.1 & 6.8 & 65 & 10.9 & 61 \\
\hline 21 & Tianjin & 11 & 8.7 & 1.3 & 6.2 & 65 & 10.3 & 60 \\
\hline 22 & Anhui & 11 & 15.7 & 17.8 & 7.2 & 65 & 68.6 & 60 \\
\hline 23 & Hebei & 11 & 11.5 & 1.9 & 8.7 & 65 & 15.8 & 60 \\
\hline 24 & Shanxi & 11 & 12.3 & 1.2 & 10.4 & 65 & 14.2 & 60 \\
\hline 25 & Shanghai & 11 & 6.8 & 0.8 & 5.7 & 65 & 8.1 & 55 \\
\hline 26 & Xinjiang & 11 & 13.5 & 2.9 & 9.4 & 63 & 18.8 & 59 \\
\hline 27 & Yunnan & 11 & 16.0 & 4.5 & 10.9 & 62 & 26.3 & 60 \\
\hline 28 & Fujian & 11 & 9.1 & 2.4 & 7.4 & 63 & 15.3 & 60 \\
\hline
\end{tabular}


Table 2. Posterior Means and Standard Deviations ${ }^{\mathrm{a}}$

\begin{tabular}{|c|c|c|c|c|c|c|c|c|c|}
\hline Province & $\begin{array}{c}\text { National Policy } \\
\text { Elasticity (g) }\end{array}$ & $\begin{array}{l}\text { Mean } \\
(\mathrm{m})\end{array}$ & $\begin{array}{c}\text { Correlation } \\
(\mathrm{r})\end{array}$ & $\mathrm{s}^{2}(\mathrm{v})$ & Province & $\begin{array}{c}\text { National Policy } \\
\text { Elasticity (g) }\end{array}$ & $\begin{array}{l}\text { Mean } \\
(\mathrm{m})\end{array}$ & $\begin{array}{c}\text { Correlation } \\
(\mathrm{r})\end{array}$ & $\mathrm{s}^{2}(\mathrm{v})$ \\
\hline Heilongjiang & $\begin{array}{l}0.698 \\
0.574\end{array}$ & $\begin{array}{l}2.297 \\
0.138\end{array}$ & $\begin{array}{c}-0.122 \\
0.481\end{array}$ & $\begin{array}{l}0.054 \\
0.036\end{array}$ & Jiangsu* & $\begin{array}{l}1.417 \\
0.667\end{array}$ & $\begin{array}{l}2.427 \\
0.220\end{array}$ & $\begin{array}{l}0.323 \\
0.430\end{array}$ & $\begin{array}{l}0.057 \\
0.035\end{array}$ \\
\hline Jilin & $\begin{array}{l}0.408 \\
0.714\end{array}$ & $\begin{array}{l}2.304 \\
0.191\end{array}$ & $\begin{array}{l}0.161 \\
0.436\end{array}$ & $\begin{array}{l}0.079 \\
0.049\end{array}$ & Guizhou** & $\begin{array}{l}3.165 \\
0.846\end{array}$ & $\begin{array}{l}2.915 \\
0.311\end{array}$ & $\begin{array}{l}0.551 \\
0.305\end{array}$ & $\begin{array}{l}0.072 \\
0.049\end{array}$ \\
\hline Liaoning & $\begin{array}{l}1.066 \\
0.891\end{array}$ & $\begin{array}{l}2.231 \\
0.201\end{array}$ & $\begin{array}{l}0.078 \\
0.433\end{array}$ & $\begin{array}{l}0.118 \\
0.072\end{array}$ & Sichuan* & $\begin{array}{l}2.384 \\
1.010\end{array}$ & $\begin{array}{l}2.809 \\
0.398\end{array}$ & $\begin{array}{l}0.620 \\
0.216\end{array}$ & $\begin{array}{l}0.139 \\
0.090\end{array}$ \\
\hline Neimenggu & $\begin{array}{l}0.207 \\
0.596\end{array}$ & $\begin{array}{l}2.244 \\
0.137\end{array}$ & $\begin{array}{c}-0.084 \\
0.455\end{array}$ & $\begin{array}{l}0.059 \\
0.038\end{array}$ & Guangxi** & $\begin{array}{l}2.279 \\
0.756\end{array}$ & $\begin{array}{l}2.552 \\
0.262\end{array}$ & $\begin{array}{l}0.460 \\
0.367\end{array}$ & $\begin{array}{l}0.062 \\
0.039\end{array}$ \\
\hline Gansu** & $\begin{array}{l}3.095 \\
0.927\end{array}$ & $\begin{array}{l}2.669 \\
0.257\end{array}$ & $\begin{array}{l}0.205 \\
0.410\end{array}$ & $\begin{array}{l}0.108 \\
0.071\end{array}$ & Guangdong* & $\begin{array}{l}1.458 \\
0.656\end{array}$ & $\begin{array}{l}2.221 \\
0.245\end{array}$ & $\begin{array}{l}0.437 \\
0.390\end{array}$ & $\begin{array}{l}0.056 \\
0.035\end{array}$ \\
\hline Shaanxi & $\begin{array}{l}0.702 \\
0.692\end{array}$ & $\begin{array}{l}2.433 \\
0.264\end{array}$ & $\begin{array}{l}0.534 \\
0.315\end{array}$ & $\begin{array}{l}0.067 \\
0.041\end{array}$ & Beijing & $\begin{array}{l}0.424 \\
0.615\end{array}$ & $\begin{array}{l}2.103 \\
0.202\end{array}$ & $\begin{array}{l}0.297 \\
0.450\end{array}$ & $\begin{array}{l}0.054 \\
0.033\end{array}$ \\
\hline Qinghai** & $\begin{array}{l}3.890 \\
0.945\end{array}$ & $\begin{array}{l}2.507 \\
0.293\end{array}$ & $\begin{array}{l}0.348 \\
0.391\end{array}$ & $\begin{array}{l}0.085 \\
0.058\end{array}$ & Tianjin & $\begin{array}{l}0.816 \\
0.607\end{array}$ & $\begin{array}{l}2.079 \\
0.231\end{array}$ & $\begin{array}{l}0.456 \\
0.393\end{array}$ & $\begin{array}{l}0.049 \\
0.030\end{array}$ \\
\hline Ningxia & $\begin{array}{l}1.040 \\
0.692\end{array}$ & $\begin{array}{l}2.429 \\
0.230\end{array}$ & $\begin{array}{l}0.394 \\
0.371\end{array}$ & $\begin{array}{l}0.067 \\
0.043\end{array}$ & Anhui** & $\begin{array}{l}4.171 \\
1.053\end{array}$ & $\begin{array}{l}2.496 \\
0.240\end{array}$ & $\begin{array}{c}-0.228 \\
0.401\end{array}$ & $\begin{array}{l}0.148 \\
0.116\end{array}$ \\
\hline Henan** & $\begin{array}{l}3.086 \\
0.830\end{array}$ & $\begin{array}{l}2.517 \\
0.223\end{array}$ & $\begin{array}{l}0.015 \\
0.462\end{array}$ & $\begin{array}{l}0.080 \\
0.054\end{array}$ & Hebei* & $\begin{array}{l}1.174 \\
0.589\end{array}$ & $\begin{array}{l}2.404 \\
0.207\end{array}$ & $\begin{array}{l}0.288 \\
0.474\end{array}$ & $\begin{array}{l}0.046 \\
0.028\end{array}$ \\
\hline Shandong* & $\begin{array}{l}1.542 \\
0.665\end{array}$ & $\begin{array}{l}2.587 \\
0.255\end{array}$ & $\begin{array}{l}0.496 \\
0.368\end{array}$ & $\begin{array}{l}0.052 \\
0.032\end{array}$ & Shanxi & $\begin{array}{l}0.657 \\
0.547\end{array}$ & $\begin{array}{l}2.482 \\
0.184\end{array}$ & $\begin{array}{l}0.222 \\
0.502\end{array}$ & $\begin{array}{l}0.043 \\
0.026\end{array}$ \\
\hline Hunan** & $\begin{array}{l}2.336 \\
0.737\end{array}$ & $\begin{array}{l}2.569 \\
0.243\end{array}$ & $\begin{array}{l}0.383 \\
0.377\end{array}$ & $\begin{array}{l}0.063 \\
0.040\end{array}$ & Shanghai & $\begin{array}{l}0.095 \\
0.569\end{array}$ & $\begin{array}{l}1.842 \\
0.219\end{array}$ & $\begin{array}{l}0.465 \\
0.367\end{array}$ & $\begin{array}{l}0.046 \\
0.028\end{array}$ \\
\hline Hubei* & $\begin{array}{l}1.898 \\
0.684\end{array}$ & $\begin{array}{l}2.408 \\
0.188\end{array}$ & $\begin{array}{l}0.149 \\
0.408\end{array}$ & $\begin{array}{l}0.061 \\
0.040\end{array}$ & Xinjiang & $\begin{array}{l}1.114 \\
0.741\end{array}$ & $\begin{array}{l}2.559 \\
0.210\end{array}$ & $\begin{array}{l}0.236 \\
0.414\end{array}$ & $\begin{array}{l}0.080 \\
0.018\end{array}$ \\
\hline Jiangxi* & $\begin{array}{l}1.059 \\
0.564\end{array}$ & $\begin{array}{l}2.407 \\
0.203\end{array}$ & $\begin{array}{l}0.422 \\
0.363\end{array}$ & $\begin{array}{l}0.042 \\
0.025\end{array}$ & Yunnan* & $\begin{array}{l}1.683 \\
0.746\end{array}$ & $\begin{array}{l}2.741 \\
0.240\end{array}$ & $\begin{array}{l}0.375 \\
0.372\end{array}$ & $\begin{array}{l}0.076 \\
0.048\end{array}$ \\
\hline Zhejiang* & $\begin{array}{l}0.879 \\
0.550\end{array}$ & $\begin{array}{l}2.212 \\
0.190\end{array}$ & $\begin{array}{l}0.331 \\
0.419\end{array}$ & $\begin{array}{l}0.041 \\
0.024\end{array}$ & Fujian* & $\begin{array}{l}1.506 \\
0.692\end{array}$ & $\begin{array}{l}2.178 \\
0.237\end{array}$ & $\begin{array}{l}0.414 \\
0.370\end{array}$ & $\begin{array}{l}0.064 \\
0.039\end{array}$ \\
\hline
\end{tabular}

${ }^{\mathrm{a}}$ Numbers in italics are standard deviations of the paramaters' marginal posterior distributions.

A "*" next to a province's name indicates that the posterior distribution of its national policy elasticity has more than $95 \%$ of its mass to the right of zero. A "**" indicates that more than $95 \%$ of its mass lies to the right of one. 
Table 3.Estimated Total Excess Deaths and Fraction Attributable to National Policy

\begin{tabular}{lllc}
\hline \hline Province & $\begin{array}{l}\text { Pop 54 } \\
(10,000 ' s)\end{array}$ & $\begin{array}{l}\text { Excess Deaths } \\
(1959-1961)\end{array}$ & $\begin{array}{c}\text { Percent of Excess Deaths } \\
\text { due to National Effect }\end{array}$ \\
\hline Heilongjiang & 1250 & 4206 & $100 \%$ \\
Jilin & 1165 & 79365 & $30 \%$ \\
Liaoning & 2153 & 319271 & $37 \%$ \\
Neimenggu & 802 & 0 & NA \\
Gansu & 1118 & 440875 & $87 \%$ \\
Shaanxi & 1651 & 34895 & $100 \%$ \\
Qinghai & 173 & 66455 & $100 \%$ \\
Ningxia & 158 & 20093 & $56 \%$ \\
Henan & 4560 & 1328600 & $100 \%$ \\
Shandong & 5052 & 1005344 & $61 \%$ \\
Hunan & 3430 & 380470 & $100 \%$ \\
Hubei & 2852 & 358608 & $100 \%$ \\
Jiangxi & 1730 & 0 & $\mathrm{NA}$ \\
Zhejiang & 2326 & 0 & $\mathrm{NA}$ \\
Jiangsu & 3891 & 467728 & $77 \%$ \\
Guizhou & 1557 & 775191 & $82 \%$ \\
Sichuan & 6649 & 6867908 & $37 \%$ \\
Guangxi & 2018 & 493143 & $83 \%$ \\
Guangdong & 3357 & 229390 & $100 \%$ \\
Beijing & 540 & 8154 & $100 \%$ \\
Tianjin & 478 & 2624 & $100 \%$ \\
Anhui & 3149 & 1772662 & $94 \%$ \\
Hebei & 3443 & 258646 & $92 \%$ \\
Shanxi & 1465 & 7971 & $100 \%$ \\
Shanghai & 958 & 0 & NA \\
Xinjiang & 500 & 18168 & $90 \%$ \\
Yunnan & 1768 & 281742 & $69 \%$ \\
Fujian & 1339 & 132059 & \\
\hline & & & $90 \%$ \\
Aggregate & 59529 & $15,353,567$ & \\
\hline
\end{tabular}

*NA indicates that the province experienced no excess deaths. 
Figure 1. Index of National Policy Effect on Mortality

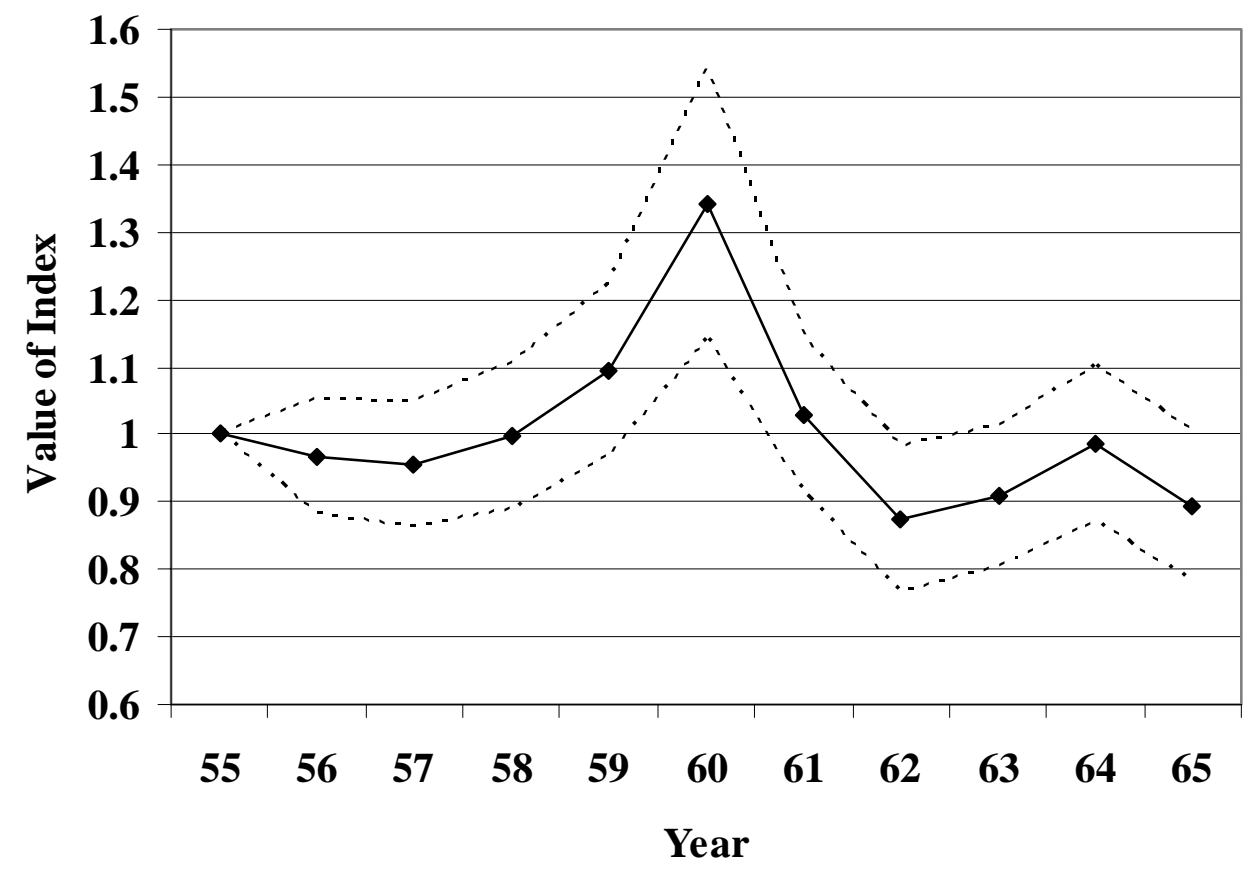


Figure 2 Weather and Predicted Weather by Province Excluding Sichuan

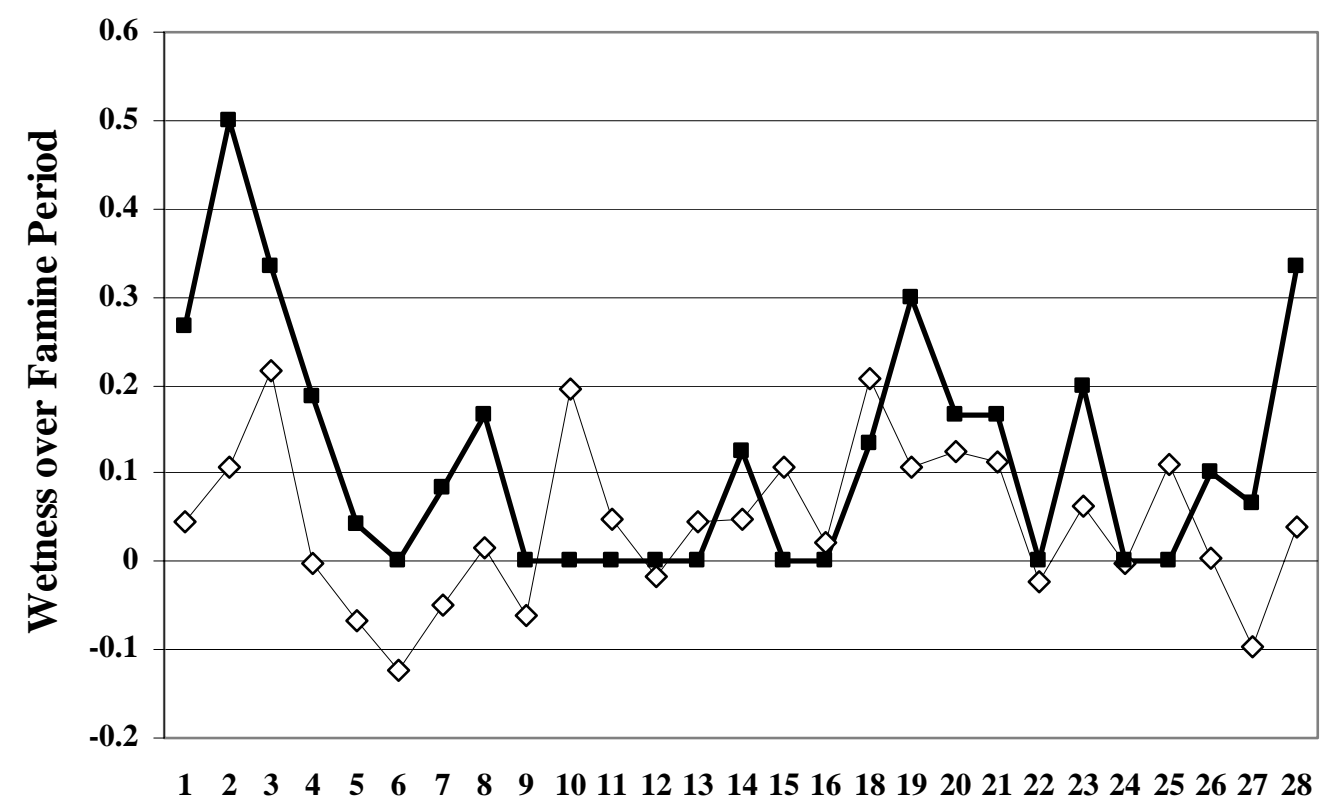

Province Number from Table 1

$\diamond$ Predicted Weather 59-61 $\rightarrow-$ Wetness 59-61 


\section{NOTES}

1 "The term, Great Leap Forward", is a shorthand expression for the "Three Red Banner Campaigns" invoked during China's 5-year policy period from 1958 to 1962 . One of the three campaigns, the "Great Leap Forward" was conceived in the Winter of 1957 and officially launched in February 1958. The second campaign was the "movement for socialist construction" which was launched in May 1958. The third campaign was the "commune movement" begun in May 1958. In addition to these three major policy campaigns, China's government also during this period diverged from the standard Soviet planning model and announced drastic administrative decentralization objectives. They also broke off relations with the Soviet Union. Thus, China during the years 1958 to 1961 witnessed tumultuous change on many levels. The next period entitled, "Recovery and Readjustment" (started one year early due to the Leap's disasters) testifies to the Leap's negative outcomes.

${ }^{2}$ This broad policy hypothesis is in line with the majority of the qualitative Leap literature and other non-Leap-specific quantitative analyses of China's post-1949 political economic performance. For the former, see Ashton et al. (1984), Bernstein (1984), Lardy (1987), and MacFarquhar (1983). For the latter, see Chow and Kwan (1996).

${ }^{3}$ See Lardy (1987) and Yao (1999).

${ }^{4}$ Since our priors are guided by our reading of the qualitative literature, and since they are in any event dominated by the information contained in the data, we do not pursue a prior sensitivity analysis in this paper. The Gibbs sampler draw sequence, from which a prior sensitivity analysis can be constructed, are available from the authors on request. 
${ }^{5}$ Generally, provinces in the Northeast, Northwest, and South showed wetter than normal precipitations while provinces in the North, Center, and East showed drier than normal conditions during the famine period. Southwest provinces (Guizhou, Sichuan, and Yunnan) showed near normal precipitation levels.

${ }^{6}$ The R-squared of this regression is 0.15 , and the intercept is statistically insignificant.

${ }^{7}$ For further discussion on this point see Wheatcroft (1999) and Lin and Yang (2000).

${ }^{8}$ Influenza pandemics can be extreme, but the disease usually accounts for only a minority percentage of all deaths, and these are usually short-lived (although there can be "echos"). The influenza pandemic peaked in many countries around the world in 1957. In Hong Kong and Guatemala, the peak was in 1958. Pneumonia and influenza-related mortality effects varied between an 8.5\% increase in British Guiana and 124\% increase in Finland. See Sands and Buelow (1997) for a discussion of the flu and its possible China effects.

${ }^{9}$ Our results also cast light on another interesting Leap phenomenon, namely, the existence of conflicting eyewitness reports about the Leap. While some parties report readily observable demographic crisis circumstances, other parties report a complete lack of such circumstances. See Becker (1996) for the former, and Lin and Yang (2000) for examples of the latter. Our study suggests that conflicting regional-based observations could occur. 